\title{
THE LIMITS OF PERCEPTION OF MUSICAL TONES BY THE HUMAN EAR.
}

BY LAURENCE TURNBULL, M. D.,

Aural Surgeon to the Jefferson Medical College Hospital, Philadelphia; Physician to Howard Hospital, etc.

In many cases of ear trouble it is desirable to have means of determining the acuteness of hearing, both for ascertaining the present condition of the aural apparatus, and for the establishment of data that shall be sufficiently accurate to determine and record the progress of the patient from day to day, and to establish a standard of comparison with other cases. For this purpose the steel rods of Dr. König, of Paris, afford in many respects the most readily available and convenient means either for clinical or office use. The rods employed by me in these experiments were made of choice, white, tempered steel, under the direction of Dr. Clarence J. Blake, of Boston, and have proved perfectly satisfactory. These are held suspended by a silk thread, either close to the ear, or at a definite distance, say thirty-five feet, from the patient, and then tapped on the end with a little steel hammer, which causes a clear, ringing over-tone like a bell. They are two $\mathrm{cm}$. in diameter, and from one to four inches in length, so that they regularly increase from twenty thousand to sixty thousand vibrations in the second, according to their size. This method of examination only determines the limit of the power of perceiving musical tones, or what is technically called the pitch; it is not intended to supersede the tuningfork, or the ticking of a watch, or even the use of the voice, which determines the power of recognition of the quality and of the intensity of sounds.

In Savart's classical experiments with the toothed wheel, the lowest distinctly musical note was determined to be one of eight vibrations in a second; the highest was estimated at twenty-four thousand vibrations per second. Helmholtz fixed the lowest limit at sixteen, and the highest at thirty-eight thousand. Vierordt considered the highest to be forty-eight thousand, and Desprets as seventy-three thousand seven hundred. Dr. Blake found the perceptive power of the normal ear to vary considerably with the age, being greatest at the age of twelve or thirteen years, and diminishing in advanced life.

From a number of experiments made some years ago, ${ }^{1}$ and those I have made since, $I$ have obtained some interesting results. In the first place, my extended experience with this means of testing the acuteness of the hearing has further confirmed me in my preference for König's rods. In using them $I$ observe the precaution to have their tempera-

I See Proceedings of the American Association for the Adrancement of Science, Hartford meeting, August, 1874. 
ture at different observations to correspond as nearly as possible, in order to prevent any source of fallacy from their change in shape. ${ }^{1}$ In the second place, the tympanum should always be previously examined, and if any morbid condition exists it should be entered in the notes in recording the observation; of course, if the canal be obstructed by cerumen or any morbid growth, no satisfactory determination can be made until after it is cleared.

Observing these precautions, I have found that the averages of each set of my experiments, while they varied slightly from each other, were generally higher than those of Dr. Blake. In one case sixty thousand vibrations were heard by a gentleman twenty-six years of age, who was a skilled musician, and another gentleman, with a trained ear, distinguished the same tone; in quite a number fifty thousand were readily detected; in others twenty-five thousand was the extreme limit of perception. Many who were found to fall far below the average had never suffered from ear trouble, and believed their hearing to be perfectly normal. It would appear that there are a certain number of persons who are naturally insensible to sounds above a certain pitch, just as there are some who cannot distinguish between different-colored rays of light of high refractive powers, - that there is a Daltonism of the ear as well as of the eye. The analogy existing between the ability to recognize colors and that of discriminating between different musical tones has been frequently observed, and Dr. Pliny Earle ${ }^{2}$ has collected an interesting series of cases, in which the two defects coexisted in the same individual (that is, where a person who was color-blind also had " no ear for music"). Apart from these exceptional cases, I have concluded from a number of observations that education of the ear has much to do with the acuteness of hearing; this is so true that a person who first tests his hearing with the rods may find that he is unable to distinguish tones higher than a certain pitch, say thirty thousand per

1 Nor should it be overlooked that the condacting power of the air is greatly affected by its temperature. It will be interesting in this connection to compare the results obtained under different temperatures. If air be heated it expands and becomes lighter, and the sound travels more rapidly than through cold air. The late $M$. Wertheim determined the velocity of sonnd in air of different temperatures as follows :-

\begin{tabular}{|c|c|c|}
\hline \multicolumn{3}{|c|}{ Temperature of Air. } \\
\hline $1.5^{\circ}$ & Centigrade & $\left(34.7^{\circ}\right.$ F. $)$ \\
\hline 2.10 & “ & $\left(35.8^{\circ} \mathrm{F}.\right)$ \\
\hline 85 & “ & $\left(47.3^{\circ}\right.$ F. $)$ \\
\hline 12.0 & “ & $\left(53.6^{\circ} \mathrm{F} .\right)^{\prime}$ \\
\hline 26.0 & “ & $\left(78.8^{\circ}\right.$ F. $)$ \\
\hline
\end{tabular}

Velocity of Sound.
1089 feet.
1091 "
1109 "
1113 "6
1140 “

At a temperature of one degree and a half above zero, the velocity is 1089 feet a second; at a temperature of $\mathbf{2 6 . 6}$ degrees it is 1140 feet a second, or a difference of 51 for 16 degrees, that is to say, an augmentation of velocity of about two feet for every single degree centigrade. Augmentation of density always produces a diminution of velocity.

2 Am. Jour. Med. Sciences, vol. xxxy., from Carpenter's Physiology, page 792. Philadelphia, 1876. 
second; but in the course of an hour or so, if he practice with them continually, he may distinguish thirty-five thousand without especial difficulty.

Cases then divide themselves in their acuteness of perception of high tones into three classes : (1.) Ordinary patients, or hospital cases from the lower walks of life, all of whose perceptions are more or less dulled, the ear being no exception. (2.) Cultivated and refined people, who have no special musical training. (3.) Skilled and professional musicians.

Physicians whose ears have been trained in auscultation and percussion, so as to recognize nice distinctions of pitch, would form a class intermediate between two and three. The fact that my observations have been, in a late series of experiments, made largely upon professional men will explain why the general results are higher than those of other observers. I have in another place ${ }^{1}$ called attention to the painful character of the impression made by these high tones in some cases. Indeed, an annoying tinnitus may result and continue for several hours, or longer.

In the following series the subjects were all scientific men, either physicians or students. The rods were held within two inches of the ear; their temperature was about $70^{\circ} \mathrm{F}$. The observations were conducted in a room remote from noise; weather cloudy and drizzling.

\begin{tabular}{|c|c|c|c|}
\hline From 20 to 30 & $\begin{array}{l}\text { Years. } \\
\qquad \begin{array}{l}22 \\
23 \\
24 \\
24 \\
24 \\
24 \\
25 \\
26 \\
26 \\
26 \\
28 \\
29 \\
29 \\
30 \\
30 \\
30 \\
30 \\
30\end{array}\end{array}$ & $\begin{array}{l}\text { Instial. } \\
\text { G. H. R. } \\
\text { A. DE W. } \\
\text { D. J. } \\
\text { J. M. } \\
\text { J. M. S. } \\
\text { H. F. S. } \\
\text { J. M. B. } \\
\text { J. E. F. } \\
\text { A. O. } \\
\text { H. P. } \\
\text { I. O. } \\
\text { J. S. T. } \\
\text { C. M. T. } \\
\text { F. W. } \\
\text { J. E. W. } \\
\text { C. S. T. } \\
\text { W. S. L. } \\
\text { G. A. N. }\end{array}$ & $\begin{array}{c}\text { Vibrations. } \\
\mathbf{5 0 , 0 0 0} \\
\mathbf{5 0 , 0 0 0} \\
\mathbf{5 5 , 0 0 0} \\
\mathbf{4 0 , 0 0 0} \\
\mathbf{3 5 , 0 0 0} \\
\mathbf{5 5 , 0 0 0} \\
\mathbf{5 0 , 0 0 0} \\
\mathbf{4 0 , 0 0 0} \\
\mathbf{4 5 , 0 0 0} \\
60,000 \\
40,000 \\
40,000 \\
45,000 \\
40,000 \\
45,000 \\
40,000 \\
\mathbf{5 0 , 0 0 0} \\
\mathbf{3 0 , 0 0 0}\end{array}$ \\
\hline From 30 to 50 & $\left\{\begin{array}{l}32 \\
36 \\
39 \\
47 \\
48\end{array}\right.$ & $\begin{array}{l}\text { G. McC.2 } \\
\text { J. R. } \\
\mathbf{W} . \mathbf{K} . \\
\text { J. A. M. } \\
\text { R. M. S. }\end{array}$ & $\begin{array}{l}35,000 \\
40,000 \\
50,000 \\
40,000 \\
40,000\end{array}$ \\
\hline Above 50 & $\left\{\begin{array}{l}52 \\
57\end{array}\right.$ & $\begin{array}{l}\text { E. R. } \\
\text { L. T. }\end{array}$ & $\begin{array}{l}45,000 \\
30,000\end{array}$ \\
\hline
\end{tabular}

It is of interest to note that in several of the cases where a marked difference was observed between the two ears that it was in favor of

1 Proceedings of the American Association for the Advancement of Science, Hartford moeting, Angust, 1874.

2 Had ear trouble when a child; there was opacity and sinking in of membrane.

- M stands for musician. 
the left, with the single exception of the case of the gentleman who distinguished sixty thousand with his right ear who could get no higher than fifty-five thousand with his left.

The marked difference between the limit at twenty-two and that at fifty-seven years is believed not to be simply due to senile thickening of the membrana tympani, but also to a gradual narrowing and change of shape in the auditory meatus, together with alterations in the middle ear, and diminished susceptibility of the auditory nerve incident upon advancing years.

\section{RECENT PROGRESS IN PATHOLOGY AND PATHOLOGICAL ANATOMY.}

BY R. H. FITZ, M. D.

\section{PATHOLOGICAL ANATOMY.}

Jaundice from Urobiline. - In 1857 a special form of jaundice was described by Gubler under the name " ictére homophéique," and characterized by the absence of ordinary biliary coloring matter from the urine. The clinical features of this form of icterus and its distinction from ordinary jaundice have recently been stated elaborately by Dreyfus-Brisac. According to him, the color of the skin is of a dirty yellow or pale yellow, without the greenish tint which is usually present in ordinary jaundice. There is neither itching nor a slow pulse; the stools are not clay-colored, and the urine is of an amber-yellow or brownish yellow, without any greenish tint, and stains linen of a pale salmon color. The nitrous acid test of Gmelin produces no specific reaction, and merely a reddish-brown hue results in the addition of nitric acid. Chloroform extracts from the urine a brownish-red coloring matter, which becomes of a rose color when acted upon by nitric acid.

This statement of two forms of icterus corresponds with the view which has long been entertained that a jaundice may exist independent of any direct participation of the liver, and due to the transformation of blood pigment which has been set free by the destruction of numerous red blood corpuscles, - a destruction expressed by the terms hæmatogenous and hepatogenous. Poncet was the first to demonstrate that jaundice follows extensive hæmorrhages, that the discoloration depends upon the modified blood pigment, and that the pigment eliminated with the urine is like the so-called urobiline.

Gerhardt ${ }^{2}$ has also, for several years, repeatedly directed his attention to the examination of the urinary coloring matter in jaundice, and has come to the conclusion that when the urine from cases of icterus

1 Concluded from page 715.

2 Correspondenz-Blatt des allgemeinen ärztlichen Vereins von Thuringen, 1878, xi.; Allgemeine medicinische Central-Zeitung, 1878, xcv. 1187. 